\title{
Caracterização bioclimática de microrregiões do Estado de Alagoas para o cultivo do mamoeiro
}

\author{
Gustavo Bastos Lyra ${ }^{1}$, José Leonaldo de Souza ${ }^{2(*)}$, Erikson Amorim dos Santos ${ }^{2}$ e Guilherme Bastos Lyra ${ }^{2}$ \\ ${ }^{1}$ Universidade Federal Rural do Rio de Janeiro. Rodovia BR 465, km 07, s/n, Zona Rural, CEP 23890-000 Seropédica, RJ. E-mail: gblyra@gmail.com \\ ${ }^{2}$ Universidade Federal de Alagoas. Av. Lourival Melo Mota, s/n,Tabuleiro dos Martins, CEP 57072-900 Maceió, AL. \\ E-mails: jls@ccen.ufal.br, saerikson@hotmail.com e gbastoslyra@gmail.com \\ ${ }^{(*)}$ Autor para correspondência.
}

\section{INFORMAÇÕES}

\section{História do artigo:}

Recebido em 15 de abril de 2020

Aceito em 1ํ de julho de 2020

Termos para indexação:

percentil

estatística climatológica

períodos úmido e seco

Carica papaya

\section{RESUMO}

Objetivou-se avaliar as características bioclimáticas de cinco microrregiões do Estado de Alagoas para o cultivo do mamoeiro. Avaliaram-se as microrregiões do Litoral Norte, Zona da Mata, Agreste, Sertão do Alto São Francisco e Alto Sertão Alagoano. Na caracterização climática consideraram-se períodos decendiais (10 dias) da temperatura e umidade relativa do ar, velocidade do vento e insolação e o acumulado da precipitação pluvial e da evapotranspiração de referência para séries superiores a 30 anos. Para Zona da Mata a série foi de 1973 a 2003, enquanto para as demais microrregiões as séries foram de 1977 a 2006. Determinaram-se as probabilidades de ocorrências dos elementos climáticos aos percentis P25, P50 e, ou P75. Esperou-se que a precipitação decendial (> $33 \mathrm{~mm}$ ) atenda as necessidades de água do mamão apenas em parte do período úmido do Litoral Norte (53 \%) e da Zona da Mata (44\%). A umidade relativa apresentou-se abaixo do adequado (<60\%) em 44,4 \% dos decêndios do Sertão do Alto São Francisco, coincidindo com o período de menores precipitações. No período úmido da Zona da Mata, a umidade foi acima do adequado (> $85 \%$ ), enquanto a duração diária do brilho solar (<5,5 h) foi inferior às necessidades da cultura. A Zona da Mata não apresenta características climáticas aptas ao cultivo do mamão. As demais microrregiões são aptas com restrições, principalmente, pela precipitação pluvial, sendo necessária a suplementação de água para a cultura via irrigação.

\section{Introdução}

A agricultura está entre as principais atividades socioeconômicas do Estado de Alagoas. A atividade agrícola neste Estado mostra dependência expressiva das condições cli- máticas, principalmente pela maior parte dos cultivos ser em regime de sequeiro. Nessas condições, o conhecimento das tendências sazonais e interanuais dos elementos climáticos permitem a definição de práticas agrícolas, escolha de cultivares, definição de épocas de plantio, planeja- 
mento da irrigação, manejo do solo, zoneamento agrícola e avaliação de riscos climáticos, que auxiliam a implantação de projetos e subsidiam políticas de crédito e seguridade rural (Cunha \&Assad, 2001).

$\mathrm{Na}$ caracterização climática é fundamental o conhecimento dos valores extremos dos elementos climáticos. Esses extremos podem ser obtidos por análises probabilísticas, que permitem definir seus períodos e magnitudes de ocorrências em diversos níveis de probabilidade (Souza et al., 2004). Nas análises probabilísticas, a técnica dos percentis vem sendo utilizada com frequência na determinação das probabilidades de ocorrências de valores extremos, particularmente devido à facilidade de aplicação e a consolidação dessa técnica (Xavier \& Xavier, 1987; Cardim, 2003; Souza et al., 2004).

Atualmente, a fruticultura apresenta elevada taxa de expansão das áreas cultivadas no Brasil, em particular na região Nordeste. Nesse cenário, o mamão se sobressai entre as frutas tropicais, sendo o País o principal produtor mundial, com cerca de 1,6 milhão de toneladas em uma área de 36 mil ha. Dessa produção, o mercado interno absorve a maior parte, o que é confirmado pelo volume de exportações de apenas $5 \%$ do total produzido (AGRIANU$\mathrm{AL}, 2005)$. A expansão dessa cultura para regiões como o Nordeste exige a definição de áreas onde sejam atendidas as necessidades bioclimáticas favoráveis ao crescimento regular e a produtividade econômica do mamoeiro.

O mamoeiro é planta típica de clima tropical, que necessita para o seu adequado desenvolvimento e produção de frutos de precipitação pluvial anual entre 1.200 e 2.000 $\mathrm{mm}$, distribuída regularmente durante o ano (OMM, 1991; Nishima et al., 2000; Coelho et al., 2002; SEAGRI, 2007). A temperatura do ar é um dos elementos mais importantes para essa cultura. Temperaturas do ar abaixo de $15,5 \stackrel{\circ}{ } \mathrm{C}$ podem causar carpeloidia ("cara de gato"), inibição do florescimento e do crescimento das plantas, queda dos frutos e redução no seu conteúdo de açúcar, enquanto temperaturas acima de $32 \stackrel{\circ}{\circ}$ resultam em queda de flores e indução de "esterilidade feminina", ocorrendo assim queda de produção (Nishima et al., 2000; Crane, 2005). O intervalo de temperatura considerado adequado para o seu crescimen- to e produção econômica é entre 21 e $32{ }^{\circ} \mathrm{C}$ (Marler et al., 1994; Marin et al., 1995; Nishima et al., 2000; Crane, 2005, SEAGRI, 2007).

Baixos valores de umidade relativa do ar proporcionam queda das flores do mamoeiro, enquanto umidade elevada, aumenta a incidência de doenças, como phytophora e antracnose, sendo o intervalo entre 60 e $85 \%$ considerado adequado (Siqueira \& Botrel, 1986; Medina, 1989; Oliveira et al., 1994; Nishima et al., 2000; SEAGRI, 2007). Para o seu crescimento e produção regular, a duração anual do brilho solar acima de 2.000 h é considerada suficiente, ou seja, em média 5,5 h diárias (SEAGRI, 2007).

O mamão é suscetível a danos provocados pela tensão cisalhante do vento, apresentando redução no crescimento, na qualidade dos frutos e na produtividade em locais com ventos fortes e contínuos (Nishima et al., 2000; Clemente; Marler, 2001; Crane, 2005). Em regiões costeiras, os sais marinhos carreados pelo vento podem ainda descascar folhas e frutos, e assim, causar a morte da planta, ou resultar em frutos sem valor comercial (Nishima et al., 2000; Crane, 2005). Velocidades do vento acima de $5 \mathrm{~m} \mathrm{~s}^{-1}$ resultam em diminuição significativa no crescimento do mamão, em função da diminuição da assimilação líquida de $\mathrm{CO}_{2}$ (Clemente \& Marler, 2001).

O objetivo do presente trabalho foi avaliar as características bioclimáticas de cinco microrregiões do Estado de Alagoas para o cultivo do mamoeiro.

\section{Material e Métodos}

Realizou-se a caracterização climática para cinco microrregiões do estado de Alagoas: Litoral Norte, Zona da Mata, Agreste, Sertão do Alto São Francisco e Alto Sertão Alagoano (Figura 1). Essas microrregiões foram representadas, respectivamente, pelas estações meteorológicas de Porto de Pedras, Rio Largo, Palmeira dos Índios, Pão de Açúcar e Água Branca (Tabela 1). As estações pertencem ao Instituto Nacional de Meteorologia (INMET) ou ao Centro de Ciências Agrárias da Universidade Federal de Alagoas (CECA/UFAL).
Figura 1. Localização das microrregiões de Alagoas caracterizadas climaticamente, com destaque para os municípios que as representam: Porto de Pedras (Litoral Norte), Rio Largo (Zona da Mata), Palmeira dos Índios (Agreste), Pão de Açúcar (Sertão do Alto São Francisco) e Âgua Branca (Alto Sertão Alagoano).

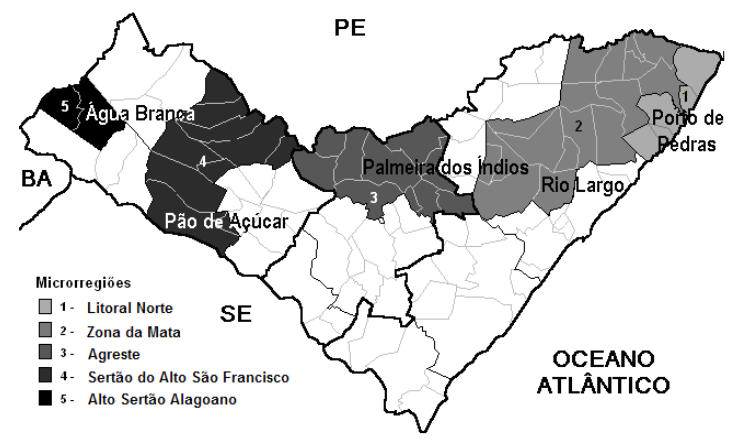


Tabela 1. Microrregiões e estações meteorológicas utilizadas para caracterização climática com as coordenadas (latitude, longitude e altitude), instituições a que pertencem as estações (Instituto Nacional de Meteorologia - INMET e Centro de Ciências Agrárias da Universidade Federal de Alagoas - CECA/UFAL) e anos da série.

\begin{tabular}{|c|c|c|c|c|}
\hline Microrregião & Estação meteorológica & $\begin{array}{l}\text { Coordenadas } \\
\text { Geodésicas }\end{array}$ & Instituição & Série \\
\hline Litoral Norte & Porto de Pedras & $9^{\circ} 13^{\prime} \mathrm{S} ; 35^{\circ} 20^{\prime} \mathrm{W} ; 22 \mathrm{~m}$ & INMET & $1977-2006$ \\
\hline Zona da Mata & Rio Largo & $9^{\circ} 27^{\prime}$ S; $35^{\circ} 27^{\prime}$ W; 127 m & CECA/UFAL & $1973-2003$ \\
\hline Agreste & Palmeira dos Índios & $9^{\circ} 25^{\prime} \mathrm{S} ; 36^{\circ} 40^{\prime} \mathrm{W} ; 311 \mathrm{~m}$ & INMET & $1977-2006$ \\
\hline Sertão do Alto São Francisco & Pão de Açúcar & $9^{\circ} 46^{\prime} \mathrm{S} ; 37^{\circ} 27^{\prime} \mathrm{W} ; 30 \mathrm{~m}$ & INMET & $1977-2006$ \\
\hline Alto Sertão Alagoano & Água Branca & $9^{\circ} 15^{\prime} \mathrm{S} ; 37^{\circ} 56^{\prime} \mathrm{W} ; 560 \mathrm{~m}$ & INMET & $1977-2006$ \\
\hline
\end{tabular}

$\mathrm{Na}$ caracterização dessas localidades utilizaram-se registros diários da duração de brilho solar ou insolação $(n, h)$, temperatura do $\operatorname{ar}\left(T,{ }^{\circ} \mathrm{C}\right)$, umidade relativa do ar (UR, \%), velocidade do vento $\left(u, \mathrm{~m} \mathrm{~s}^{-1}\right)$ e precipitação pluvial ( $\left.P, \mathrm{~mm}\right)$. Como a velocidade do vento nas estações do INMET foi medida a dez metros de altura, e em estudos agroclimáticos a referência é a velocidade a dois metros acima da superfície (Pereira et al., 1997), aplicou-se a lei logarítmica do vento para reduzir $u$ a esse nível de referência pela relação sugerida por Allen et al. (1998). Essas variáveis climatológicas foram dispostas em períodos de dez dias, decêndio ou decendial. Na definição de decêndio (d) dividiu-se o mês em três partes, sendo as duas primeiras de dez dias e a última variando de oito a 11 dias, dependendo do mês, o que totalizou 36 decêndios por ano $(d 1, d 2, . ., d 36)$.

Determinou-se também a duração do período úmido e seco das microrregiões em estudo, em função da precipitação pluvial decendial determinada ao percentil 25 (P25) e da evapotranspiração de referência $\left(E T_{\partial}, \mathrm{mm}\right)$ ao percentil 50 (P50). O início do período úmido foi considerado como o decêndio com precipitação pluvial igual ou superior a 0,5 de $E T_{0}$ decendial, sem que o decêndio posterior tivesse $P$ inferior a 0,5ET . Definiu-se o final do período úmido como o primeiro decêndio com $P$ menor que $0,5 E T_{\text {o }}$, posterior ao seu início, similar ao sugerido por diversos autores (Kassam, 1980; Simane \& Struik, 1993; Moraes et al., 2005). A evapotranspiração de referência foi estimada pelo método de Penman-Monteith, parametrizado no boletim FAO56 por Allen et al. (1998).

Determinou-se a distribuição esperada dos elementos climáticos descritos anteriormente e da evapotranspiração de referência, para os percentis de 25, 50 e, ou 75 (P75). O percentil $\left(\alpha_{\mathrm{p}}\right)$ equivalente ao valor de uma variável meteorológica continua $(X)$, que corresponde à porcentagem da área sob a curva da função de distribuição (F), foi definido como (SpiegeL, 1978):

$$
\operatorname{Prob}\left(\mathrm{X} \leq \alpha_{\mathrm{P}}\right)=\mathrm{F}\left(\alpha_{\mathrm{P}}\right)
$$

em que, $\alpha_{\mathrm{p}}$ são os valores esperados de determinado elemento climático e $p$ (\%) é a probabilidade.

As análises dos extremos da precipitação pluvial e de insolação foram realizadas ao percentil P25, ou seja, ava- liou-se a probabilidade de $75 \%$ de ocorrer valor igual ou superior para esses elementos. Para a velocidade do vento considerou-se o percentil P75, e assim, 75\% de probabilidade de se esperar valor igual ou inferior para esse elemento. No caso da temperatura e umidade relativa do ar, consideraram-se nas suas análises os percentis P25 e P75, para o limite inferior e superior, respectivamente.

Na avaliação das condições bioclimáticas consideraram-se como adequados para o crescimento e produção potencial dos frutos do mamoeiro, os seguintes limites para os elementos climáticos: precipitação pluvial decendial superior a 33,3 $\mathrm{mm}$, considerando $1.200 \mathrm{~mm}$ distribuídos regularmente durante o ano (OMM, 1991; Nishima et al., 2000; Coelho et al., 2002; SEAGRI, 2007); limite inferior da temperatura do ar média de $21^{\circ} \mathrm{C}$ e superior de $32{ }^{\circ} \mathrm{C}$ (Marler et al., 1994; Marin et al., 1995; Nishima et al. 2000; Crane, 2005; SEAGRI, 2007); umidade relativa entre 60 (inferior) e $85 \%$ (superior) (Siqueira \& Botrel, 1986; Medina, 1989; Oliveira et al., 1994; Nishima et al., 2000; SEAGRI, 2007); insolação maior ou igual a 5,5 h (SEAGRI, 2007) e velocidade do vento inferior a $5 \mathrm{~m} \mathrm{~s}^{-1}$ (Clemente \& Marler, 2001)

\section{Resultados e Discussão}

Os maiores valores decendiais de precipitação pluvial ao percentil P25 alternaram entre a Zona da Mata (Fig. 2d) e o Litoral Norte (Fig. 2e) e os menores ocorreram no Sertão do Alto São Francisco (Fig. 2b). Cardim (2003) observou que a região central da Zona da Mata apresentava precipitação superior à da microrregião do Litoral Norte, com tendência de diminuição dos totais de precipitação da Zona da Mata em direção ao interior do Estado (sentido leste-oeste). Contudo, no Alto Sertão Alagoano, extremo oeste do Estado, observou-se um núcleo com precipitação pluvial superior à das áreas no seu entorno.

As precipitações do Litoral Norte e da Zona da Mata são influenciadas pelo sistema de brisas, que associado à proximidade do ambiente costeiro, com aporte de umidade, contribui para os totais decendiais superiores às demais microrregiões. No Alto Sertão Alagoano observam-se altitudes superiores a $500 \mathrm{~m}$, com contribuição de sistemas 
Figura 2. Variação do acumulado decendial da precipitação pluvial ( $P, \mathrm{~mm})$ ao percentil P25 e da metade do acumulado decendial da evapotranspiração de referência a $P 50(0,5 E T$, mm) nas microrregiões a) Alto Sertão Alagoano, b) Sertão do Alto São Francisco, c) Agreste, d) Zona da Mata , e) Litoral Norte.
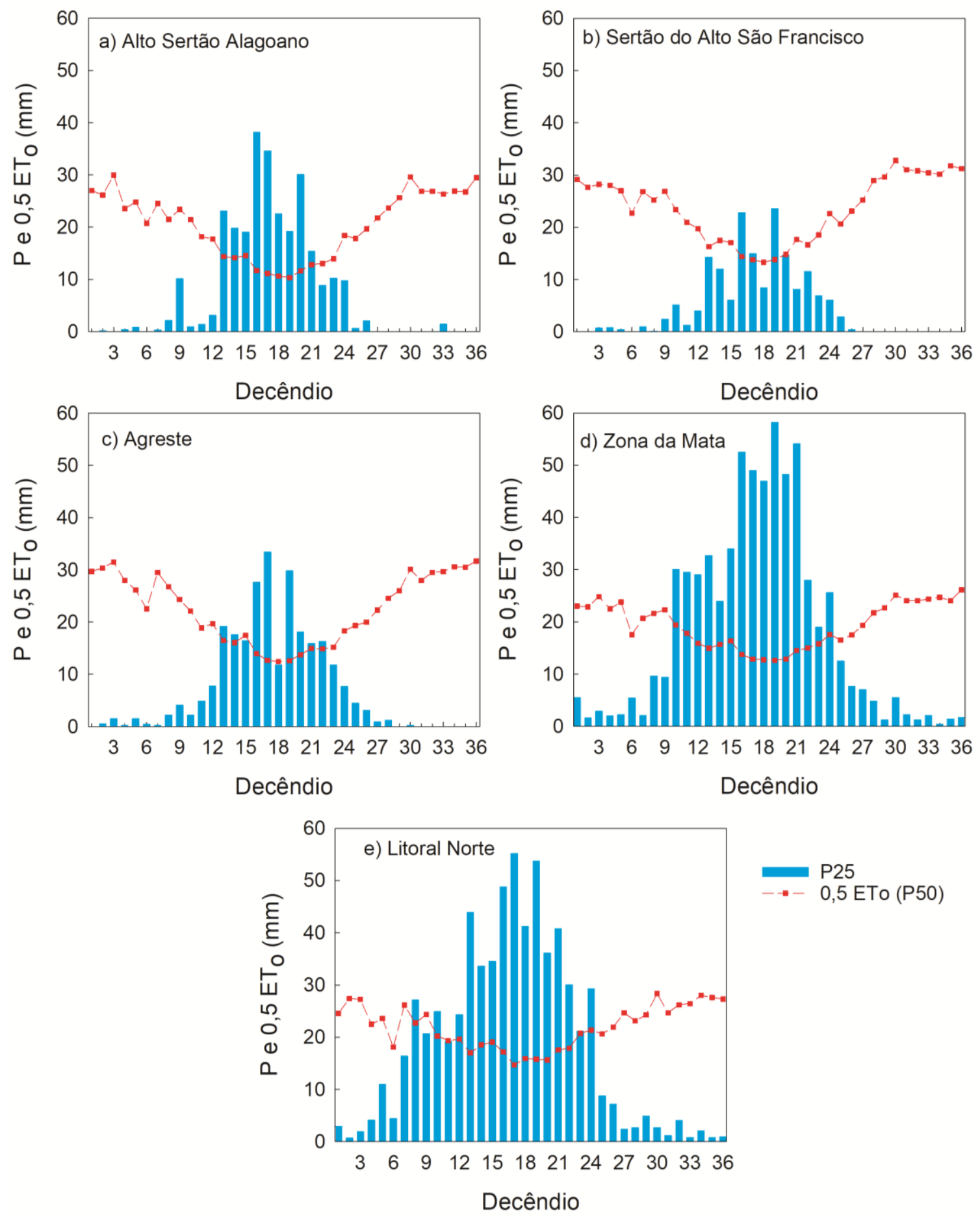

orográficos e de ventos locais na sua precipitação. Isso resultou em acumulados decendiais superiores ao do Sertão do Alto São Francisco.

Pelos critérios definidos, a microrregião do Sertão do Alto São Francisco não apresentou período úmido definido. Os maiores valores de precipitação decendial $(>9,5$ $\mathrm{mm}$ ) nessa microrregião, a P25, foram observados entre o primeiro decêndio de maio (d13) e o de agosto (d22). A pre- cipitação desses decêndios representou $81 \%$ do total anual (168,2 mm), com máximo provável de 23,6 mm, esperado no primeiro decêndio de julho (d19). 0 início do período úmido ocorreu no primeiro decêndio de abril (d10) para a Zona da Mata e no terceiro decêndio de abril (d12) para o Litoral Norte, enquanto o Alto Sertão Alagoano (Fig. 2a) e o Agreste tiveram início similar e apenas no primeiro decêndio de maio (d13). Além do início tardio, o Alto Sertão 
Alagoano e o Agreste apresentaram duração do período úmido inferior ao das demais localidades e de 90 (Alto Sertão Alagoano) e 100 dias (Agreste). O final do período úmido ocorreu no fim de julho (d21) e início de agosto (d22) para, respectivamente, o Alto Sertão Alagoano e o Agreste. No restante das microrregiões a duração do período úmido variou entre 130 dias (Litoral Norte) e 150 (Zona da Mata), sendo seu final provável no último decêndio de agosto (d24) para o Litoral Norte e para a Zona da Mata.

$\mathrm{Na}$ costa leste do Nordeste, os maiores acumulados de precipitação pluvial se concentram de abril a julho (Molion \& Bernardo, 2002). O principal mecanismo responsável pelas chuvas nesse período é a Zona de Convergência do Leste do Nordeste (ZCEN), alimentada pela convergência de umidade dos Alísios. O deslocamento da ZCEN está relacionado à penetração de frentes frias ou cavados na média troposfera, que organizam a convecção tropical. Em menor proporção, as perturbações ondulatórias nos ventos Alísios (POA`s), circulações de mesoescala (brisas marinha e terrestre) e a convecção local, associada à orografia e a convergência de umidade complementam a precipitação anual (Molion \& Bernardo, 2002).

Em Alagoas, Figueiredo (2002) definiu o período chuvoso entre abril e julho, utilizando o índice de precipitação normalizado (Nery, et al., 2002). Enquanto o seco foi de setembro a dezembro para as microrregiões do Alto Sertão Alagoano e Sertão do Alto São Francisco e de outubro a janeiro nas demais microrregiões. O período de abril a julho coincide com parte do caracterizado como úmido para as microrregiões analisadas. Contudo, no presente trabalho o período úmido se estendeu até o final de agosto na Zona da Mata e no Litoral Norte. Souza et al. (2004) avaliaram a duração da estação de crescimento de culturas agrícolas para Maceió, AL baseados em série de 1972 a 2001 e, considerando seu início o decêndio com precipitação pluvial a P25 igual ou superior a $20 \mathrm{~mm}$ ou que superou a metade da $E T_{0}$ no decêndio anterior e nos subseqüentes. Os autores observaram condições úmidas no período de $d 11$ a d24. Por outro lado, Cardim (2003) determinou o início do período úmido, utilizando abordagem similar a do presente trabalho, em d10 para o Alto Sertão Alagoano e d11 para Litoral Norte, Zona da Mata e Agreste, não sendo também observado início definido no Sertão do Alto São Francisco.

A precipitação acumulada no período úmido representou entre 74,1 \% e 86,4 \% da precipitação anual a P25 observada nas microrregiões do Litoral Norte $(664,3 \mathrm{~mm})$ e da Zona da Mata (648,5 mm), respectivamente. Para Maceió, Souza et al. (2004) observaram contribuição de $72 \%$ da precipitação pluvial do período úmido em relação ao total anual, sendo, esse valor em média 59 \% quando determinada para Alagoas (Figueiredo, 2002).

O máximo esperado (P25) de precipitação decendial no Sertão do Alto São Francisco $(23,6 \mathrm{~mm}$, d19) foi inferior à necessidade decendial do mamão (33,3 mm), considerando a lâmina de água adequada de $100 \mathrm{~mm}$ por mês (Nishina et al., 2000). No Agreste e no Alto Sertão Alagoano apenas um $(32,4 \mathrm{~mm}, \mathrm{~d} 17)$ e dois decêndios (38,2 mm, d16; 34,6 mm, d17), respectivamente, atenderam a necessidade de água para a cultura. Na microrregião da Zona da Mata esperou-se que a necessidade de água seja suprida entre d13 e d21, enquanto no Litoral Norte o suprimento adequado foi observado de $d 15$ a d21. Esses períodos representaram 44 e 53\% do período úmido da Zona da Mata e Litoral Norte, respectivamente. Ou seja, nas demais microrregiões, principalmente no Sertão do Alto São Francisco, a necessidade de suplementação de água via irrigação é superior.

De modo geral, o Litoral Norte e o Sertão do Alto São Francisco mostraram os maiores valores de insolação, enquanto os menores alternaram entre a Zona da Mata e o Alto Sertão Alagoano, para todos os níveis de probabilidade (Fig. 3a e 3b). Nas microrregiões, o valor mínimo de brilho solar provável a P25 ocorreu entre d16 (Alto Sertão Alagoano) e d19 (Litoral Norte e Zona da Mata), que correspondeu ao período entre o primeiro decêndio de junho e o segundo de agosto. Os mínimos diários variaram de 3,7 h no Alto Sertão Alagoano a 4,6 h no Litoral Norte, ou seja, existiram nessas microrregiões $75 \%$ de probabilidade de se observar insolação diária superior a 3,7 ou a 4,6 h. Nos decêndios subseqüentes, a insolação apresentou tendência de aumento, com máximos esperados a P25 entre d30 (Alto Sertão Alagoano) e d34 (Agreste), e valores diários no intervalo de 8,1 (Zona da Mata) a 9,3 h (Litoral Norte). Esse período compreendeu do final de outubro até o início de dezembro. A partir desses decêndios o padrão da insolação foi de diminuição. Tendência decendial similar a de P25 foi observada para o percentil P75.

Os períodos nos quais a insolação média decendial atendeu as necessidades médias diárias do mamão (5,5 h) foram similares para o Alto Sertão Alagoano, Sertão do Alto São Francisco e Litoral Norte. Para essas microrregiões os períodos com $n$ superior a 5,5 h, ao nível de probabilidade $P 25$, iniciaram em $d 23$ e se estenderam até o último decêndio de abril (d12) no Alto Sertão Alagoano e Sertão do Alto São Francisco e a meados do mesmo mês (d11) para o Litoral Norte. No Litoral Norte, além desse período, os decêndios 114 e d15 também atenderam as necessidades da cultura do mamão em termos de insolação. Nas demais microrregiões o período foi de d25 a d10 para o Agreste e entre o último decêndio de setembro (d27) e o último de fevereiro (d6) para a Zona da Mata. Na Zona da Mata, ainda d8 mostrou insolação superior a 5,5 h. Assim, esperou-se, a $75 \%$ de probabilidade, insolação média decendial satisfatória às necessidades do mamão entre 47,2 (Zona da Mata) e 75 \% (Litoral Norte e Sertão do Alto São Francisco) dos decêndios. 
Figura 3. Variação da insolação média decendial $(n, h)$ ao percentil a) P25 e b) P75 nas microrregiões do Alto Sertão Alagoano, Sertão do Alto São Francisco, Agreste, Zona da Mata e Litoral Norte.

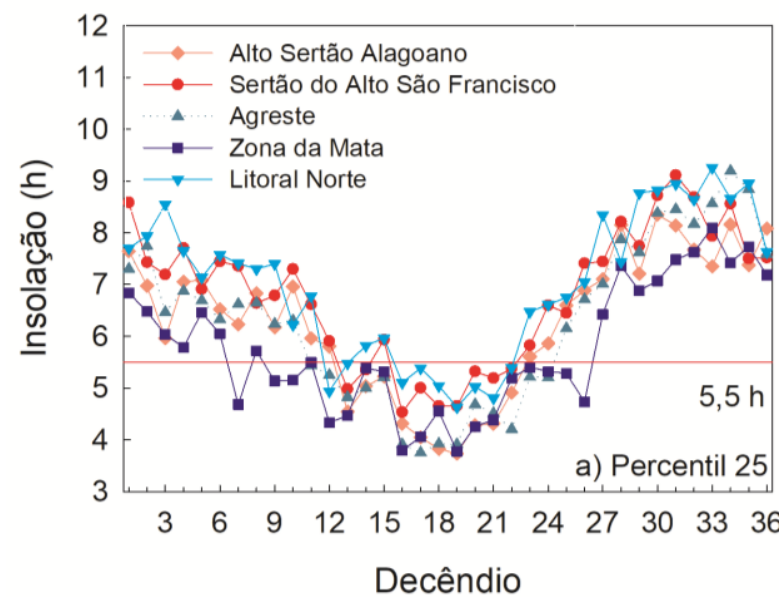

Os decêndios com $n$ superior à necessidade do mamão, coincidiram com o período seco das microrregiões, ou de menor índice pluviométrico, no caso do Sertão do Alto São Francisco, em função da menor nebulosidade esperada nesse período em relação ao período úmido. Associada a menor nebulosidade, os dias nos meses do período seco (outubro - março) são mais longos quando comparados aos do período úmido (abril - setembro). As exceções foram entre $d 8$ e $d 11, d 14$ e $d 15$ no Litoral Norte e $d 15$ no Alto Sertão Alagoano todos observados no período úmido. Assim, quando a disponibilidade de radiação solar é maior, esperaram-se os menores índices pluviométricos, o que ressalta a importância da irrigação da cultura do mamão em Alagoas para se obter maiores produtividades.

Entre as localidades, o Sertão do Alto São Francisco mostrou temperatura do ar média superior em aproximadamente 90 \% dos decêndios e percentis, enquanto, os menores valores foram observados no Alto Sertão Alagoano (Fig. 4a e 4b). Apesar do Alto Sertão Alagoano estar locali-

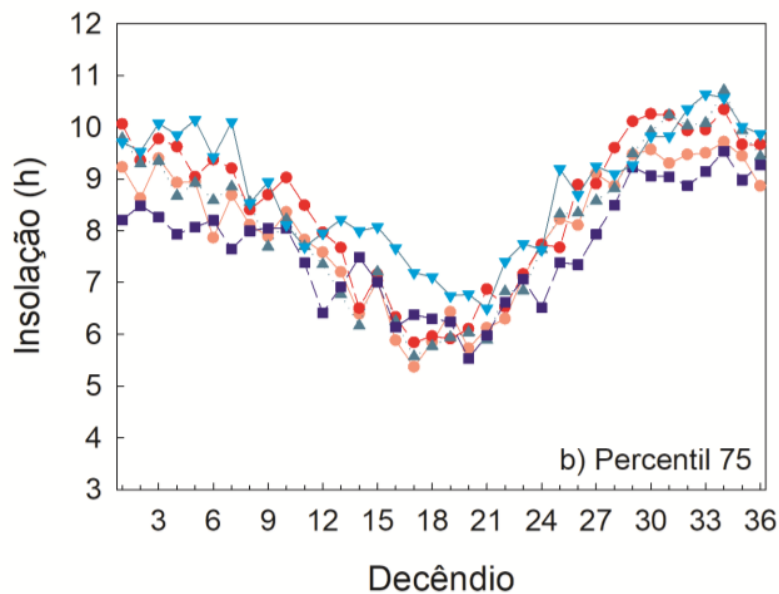

zado no extremo oeste do Estado, sua altitude acima de 500 $\mathrm{m}$, superior à das demais microrregiões, contribuiu para as temperaturas do ar inferiores. Gois et al. (2005) avaliando as médias anuais das temperaturas do ar extremas (máxima e mínima) para Alagoas, observaram seus maiores valores na microrregião do Sertão do Alto São Francisco e os menores no extremo oeste do Estado, em parte da microrregião do Alto Sertão Alagoano e no extremo nordeste da Zona da Mata, próximo à divisa com o estado de Pernambuco.

A temperatura do ar provável a P25 mostrou os maiores valores próximos ao final do ano nas microrregiões do Alto Sertão Alagoano ( $\left(34 ; 25,3^{\circ} \mathrm{C}\right)$, Litoral Norte ( 334 e d35; 26,6 $\left.{ }^{\circ} \mathrm{C}\right)$, Agreste $\left(\mathrm{d} 35 ; 27,1{ }^{\circ} \mathrm{C}\right)$ e Sertão do Alto São Francisco ( 335 e d36; 29, $2^{\circ} \mathrm{C}$ ), enquanto na Zona da Mata os maiores valores $\left(26,3^{\circ} \mathrm{C}\right)$ foram em fevereiro (d4) e março (d9) (Fig. 4a). No Agreste observou-se ainda a mesma temperatura máxima decendial em meados de janeiro (d2). A temperatura do ar mostrou tendência decendial definida, com diminuição

Figura 4. Variação da temperatura do ar $\left(T,{ }^{\circ} \mathrm{C}\right)$ média decendial aos percentis a) P25 e b) P75 nas microrregiões do Alto Sertão Alagoano, Sertão do Alto São Francisco, Agreste, Zona da Mata e Litoral Norte.
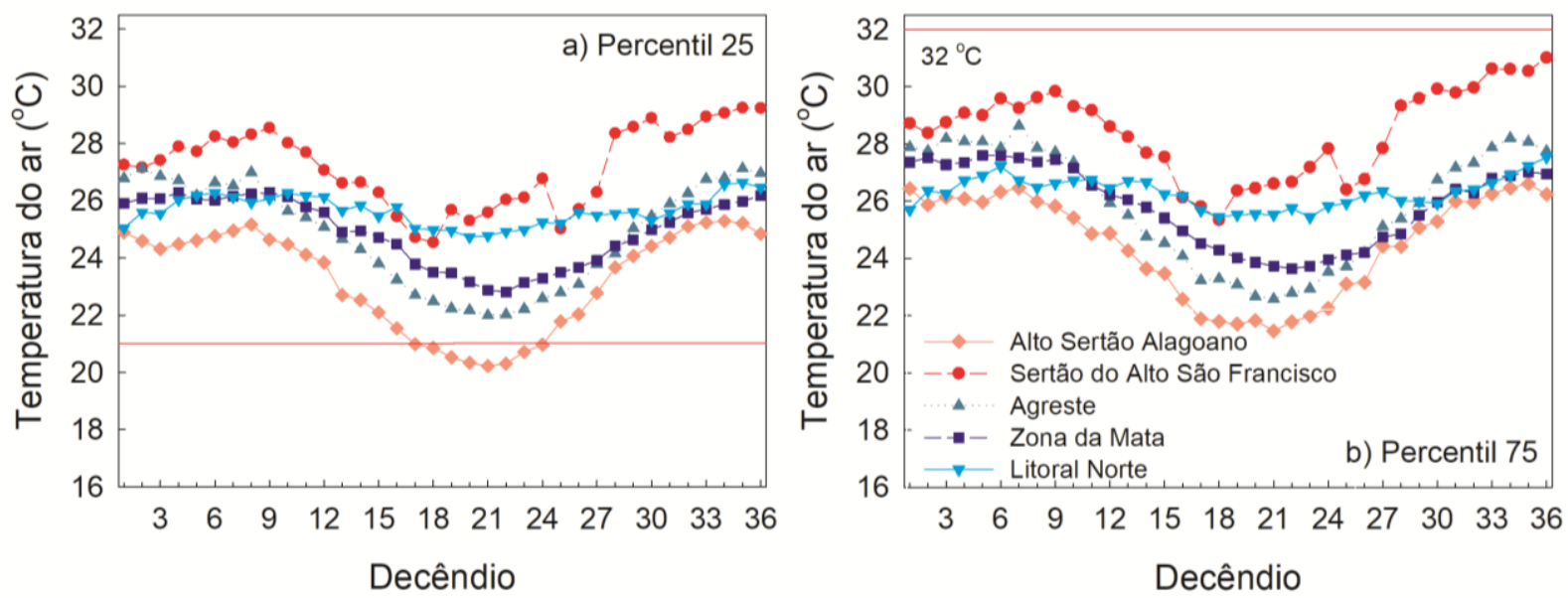
dos seus valores a partir dos decêndios de máximas e os menores valores observados entre meados de julho (d20), no Litoral Norte, e d22 na Zona da Mata e Agreste. A exceção foi no Sertão do Alto São Francisco, que mostrou o extremo inferior no último decêndio de junho (d18). Entre as localidades, os menores valores decendiais prováveis da temperatura do ar média decendial (P25) variaram de 20,2 (Alto Sertão Alagoano) a $24,7{ }^{\circ} \mathrm{C}$ (Litoral Norte). Assim, a $75 \%$ de probabilidade esperou-se que a temperatura do ar seja superior a $20,2^{\circ} \mathrm{C}$ (Alto Sertão Alagoano) e a $24,7^{\circ} \mathrm{C}$ (Litoral Norte). Desses decêndios ao final do ano a tendência da temperatura do ar foi de aumento.

Ao percentil P75 (Fig. 4b) esperaram-se os extremos inferiores de temperatura do ar nos mesmos períodos dos determinados para P25, com exceção do Litoral Norte, onde a menor temperatura média decendial ocorreu em d23. Os valores mínimos esperados a P25 foram no intervalo de 21,5 a $25,4{ }^{\circ} \mathrm{C}$, para o Alto Sertão Alagoano e o Litoral Norte, respectivamente. Os maiores valores decendiais ocorreram em dezembro para o Alto Sertão Alagoano $\left(d 35 ; 26,6{ }^{\circ} \mathrm{C}\right)$, Sertão do Alto São Francisco $\left(d 36 ; 31,0^{\circ} \mathrm{C}\right)$ e Litoral Norte $\left(d 36 ; 27,5{ }^{\circ} \mathrm{C}\right)$, em fevereiro $\left(d 5\right.$ e $\left.d 6 ; 27,6^{\circ} \mathrm{C}\right)$ para a Zona da Mata e no início de março $\left(d 7 ; 28,6^{\circ} \mathrm{C}\right)$ para o Agreste. Assim, esperou-se que a máxima temperatura média do ar provável nessas microrregiões, a $75 \%$ de probabilidade, seja menor que $26,6^{\circ} \mathrm{C}$ (Alto Sertão Alagoano) e que $31,0^{\circ} \mathrm{C}$ (Sertão do Alto São Francisco).

Souza et al. (2004), avaliando a temperatura do ar média Maceió-AL, observaram seus extremos em d21 (inferior) e $d 9$ (superior). No caso do extremo inferior, seu decêndio foi próximo do observado no presente trabalho para todas as microrregiões, enquanto o superior ocorreu próximo dos decêndios do Agreste e da Zona da Mata.

Nas microrregiões do Sertão do Alto São Francisco, Agreste, Litoral Norte e Zona da Mata esperaram-se, a P25, que a temperatura do ar média decendial seja acima do limite inferior $\left(21^{\circ} \mathrm{C}\right)$ considerado adequado para o crescimento e a produção potencial da cultura do mamoeiro durante todo o ano. Por outro lado, no Alto Sertão Alagoano, esperou-se temperatura média abaixo do limite entre d17 e d24, o que representou 22,2 \% dos decêndios. Contudo, não se observaram nessa microrregião temperaturas decendiais inferiores a $15,5^{\circ} \mathrm{C}$, o que poderia resultar em deformidade dos frutos ("cara de gato"), inibição do florescimento, queda dos frutos e redução no seu conteúdo de açúcar (Marler et al., 1994; Nishima et al., 2000; Crane, 2005; SEAGRI, 2007). A P75, o limite superior $\left(32^{\circ} \mathrm{C}\right)$ adequado não foi ultrapassado em nenhum decêndio ou microrregião. Assim, na maior parte do ano do Alto Sertão Alagoano (77,8 \% dos decêndios) a variação da temperatura do ar, a 75 \% de probabilidade, atendeu as exigências do mamão, enquanto nas demais microrregiões as exigências foram atendidas em todos os decêndios.
Independente da microrregião e do percentil, a umidade relativa do ar (UR) mostrou tendência decendial inversa à das temperaturas e influenciada pela precipitação pluvial, com os maiores valores no período úmido e os menores no seco (Fig. 5a e 5b). Os maiores valores de UR entre as microrregiões ocorreram preferencialmente na Zona da Mata, alternado com o Litoral Norte, no período seco, e com o Alto Sertão Alagoano, no período úmido. A Zona da Mata apresentou as maiores UR em média $67 \%$ dos decêndios do período seco e em 63 \% do período úmido. O Sertão do Alto São Francisco teve na maior parte dos decêndios (78 \%) os menores valores de umidade entre as microrregiões, principalmente no período seco. No restante dos decêndios (22\%), o Litoral Norte mostrou os extremos inferiores, coincidindo com parte do período úmido. Os maiores valores na Zona da Mata e Litoral Norte foram influenciados pelo índice pluviométrico anual superior ao das outras microrregiões, associado à proximidade do ambiente costeiro, notadamente no período seco do Litoral Norte.

Ao percentil P25, os menores valores prováveis da umidade média decendial do ar variaram de $52 \%$, no Sertão do Alto São Francisco a $73 \%$ no Litoral Norte. Esses valores ocorreram nos decêndios de dezembro para o Alto Sertão Alagoano (d35, 61\%), Sertão do Alto São Francisco (d34 e d35) e Zona da Mata ( $d 31$ e $d 34,69 \%$ ) e em janeiro (d2) no Litoral Norte (73\%) e Agreste (61\%). Assim, espera-se a 75\% de probabilidade valores de UR superior a $52 \%$ e a $73 \%$ no Sertão do Alto São Francisco e Litoral Norte, respectivamente. Por sua vez, os extremos superiores entre as localidades a P25 foram esperados entre 117 (80\%) e d20 (90\%), observados, respectivamente, no Litoral Norte e Alto Sertão Alagoano. Tais decêndios correspondem a observações no período úmido, como seria de se esperar.

Com exceção do Agreste, as demais microrregiões mostraram os mínimos decendiais de umidade do ar, ao percentil P75, em decêndios próximos aos observados para P25, e entre d31 (Alto Sertão Alagoano) e d35 (Zona da Mata). No Agreste, o mínimo a P75 ocorreu no final de novembro (d33). Os mínimos de UR foram entre 61 e $78 \%$, observados no Sertão do Alto São Francisco e na Zona da Mata, respectivamente. Os maiores valores a P75 foram entre 86\% (d17), no Litoral Norte, e $94 \%$ (d18 e d19), no Alto Sertão Alagoano.

O Litoral Norte, a Zona da Mata, o Agreste e o Alto Sertão Alagoano apresentaram umidade relativa do ar média decendial provável a $75 \%$ de probabilidade maior que $60 \%$ em todos os decêndios. Ou seja, nessas microrregiões o limite inferior da umidade do ar para o crescimento e desenvolvimento potencial do mamoeiro foi satisfeito. O Sertão do Alto São Francisco teve período elevado ( 44,4 \% dos decêndios, 16) com decêndios consecutivos de umidade provável abaixo do adequado, o que pode induzir a queda de flores, e dessa forma diminuição da produção (Nishina et 
Figura 5. Variação da umidade relativa do ar (UR, \%) média decendial aos percentis a) P25 e b) P75 nas microrregiões do Alto Sertão Alagoano, Sertão do Alto São Francisco, Agreste, Zona da Mata e Litoral Norte.

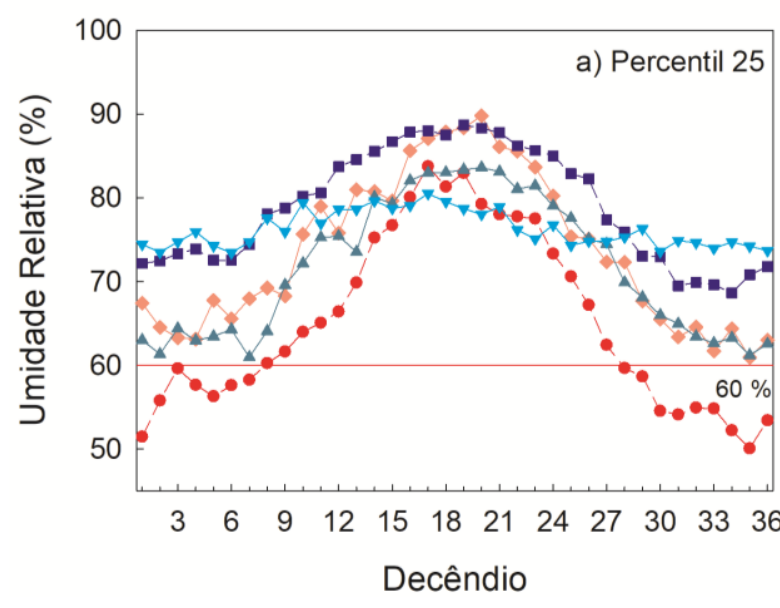

al., 2000). Esse período compreendeu os decêndios de $d 28$ a $d 7$, o que correspondeu a parte do período seco da região.

No Litoral Norte, apenas dois decêndios (d16 e d17) ultrapassaram o limite superior de umidade (85\%), a $75 \%$ de probabilidade, favorável ao crescimento regular e a produtividade ótima do mamoeiro. O Sertão do Alto São Francisco e o Agreste mostraram períodos similares nos quais a UR extrapolou o limite superior de umidade. Esses períodos se iniciaram em d16 para ambas as microrregiões e terminaram em d21 para o Sertão do Alto São Francisco e d23 para o Agreste. 0 Agreste mostrou UR superior a $85 \%$ também no primeiro decêndio de maio (d13). Os períodos de não adequação ao limite superior da umidade representaram 16,7 e $25 \%$ dos decêndios no Sertão do Alto São Francisco e no Agreste, respectivamente. Enquanto, no Alto Sertão Alagoano, a UR esperada a $75 \%$ de probabilidade foi superior a 85 $\%$ entre $d 11$ e $d 24$, o que correspondeu a $38,9 \%$ dos decêndios. A Zona da Mata teve duração do período (55,6 \% dos decêndios) com UR maior que o adequado para a cultura do mamoeiro superior ao das demais microrregiões. Esses decêndios foram observados em $d 3, d 7$ e entre $d 9$ e $d 26$. Os decêndios consecutivos com UR acima do limite adequado, principalmente na Zona da Mata e no Alto Sertão Alagoano, favorecem a incidência de doenças, como phytophora e antracnose, sendo necessário maior controle fitossanitário nessas microrregiões (Siqueira \& Botrel, 1986; Medina, 1989; Oliveira et al., 1994; Nishima et al., 2000).

Independente do percentil, a velocidade do vento $(\mathrm{u})$ entre as microrregiões apresentou os maiores valores alternando entre Alto Sertão Alagoano e Litoral Norte e os menores na Zona da Mata (Fig. 6a e 6b). Observou-se tendência decendial similar da velocidade do vento nas microrregiões da Zona da Mata, Agreste e Sertão do Alto São Francisco. Os menores valores decendiais nessas microrregiões ocorreram em parte do período úmido, com extremos

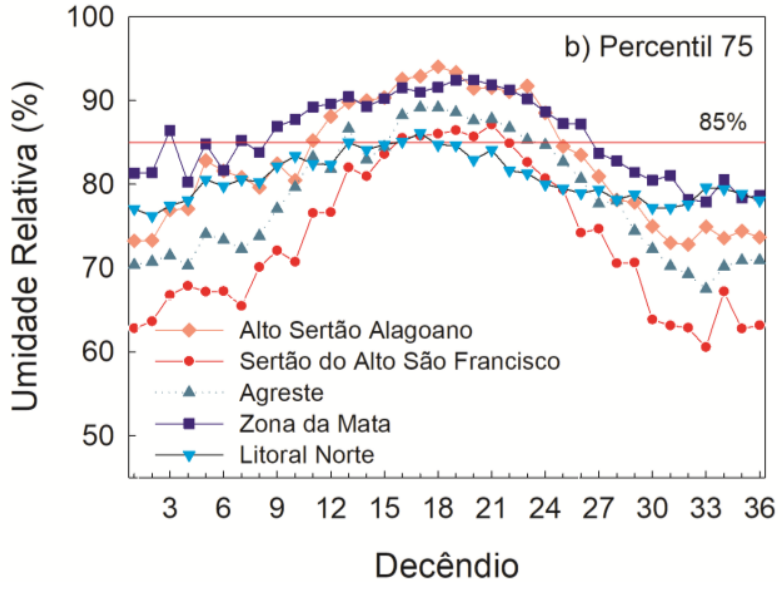

inferiores a P75 entre d13 e d22 $\left(u \leq 2,1 \mathrm{~m} \mathrm{~s}^{-1}\right)$, no Agreste e Sertão do Alto São Francisco, e de d11 a d20 $\left(u \leq 1,3 \mathrm{~m} \mathrm{~s}^{-1}\right)$ na Zona da Mata. Posterior a esses decêndios, a velocidade do vento apresentou aumento, com máximos entre novembro e dezembro para o Agreste $\left(\geq 3,5 \mathrm{~m} \mathrm{~s}^{-1}\right.$; d31 - d34) e Zona da Mata $\left(\geq 1,8 \mathrm{~m} \mathrm{~s}^{-1} ; d 31-d 35\right)$ e entre meados de outubro (d29) e $d 33$ no Sertão do Alto São Francisco $\left(\geq 2,6 \mathrm{~m} \mathrm{~s}^{-1}\right)$. A exceção foi $d 1$ no Sertão do Alto São Francisco, com velocidade do vento de $2,6 \mathrm{~m} \mathrm{~s}^{-1}$. A partir desses decêndios o padrão foi de diminuição da velocidade do vento.

A tendência decendial no Litoral Norte mostrou os menores valores da velocidade do vento a $P 75\left(<3,5 \mathrm{~ms}^{-1}\right) \mathrm{em}$ decêndios (de $d 9$ a d14) anteriores aos observados para as outras localidades, e na transição do período seco para o úmido. De d14 a d32 observou-se aumento de $u$, com os valores máximos $\left(>4,6 \mathrm{~m} \mathrm{~s}^{-1}\right)$ entre $d 28$ e $d 35$. A proximidade do Litoral Norte do ambiente costeiro, associado às características da sua tendência decendial indicam influência significativa das circulações locais (brisa marinha) no seu escoamento.

No Alto Sertão Alagoano (Fig. 6a) observou-se tendência decendial definida apenas para P75. Os menores valores de $u\left(<3,5 \mathrm{~m} \mathrm{~s}^{-1}\right)$, a esse nível de probabilidade, ocorreram na sua maioria em decêndios similares (de 114 a d20) aos observados no Agreste, Zona da Mata e Sertão do Alto São Francisco. Os períodos de menores velocidades do vento coincidiram com os de maiores precipitações pluvial, no caso do Sertão do Alto São Francisco, ou com o período úmido, no caso do Agreste, Zona da Mata e Alto Sertão Alagoano. As maiores médias decendiais da velocidade do vento para o Alto Sertão Alagoano $\left(>4,2 \mathrm{~m} \mathrm{~s}^{-1}\right)$ foram observados entre $d 28$ e d32, d34, d1 e d3, ou seja, em decêndios próximos aos de máximos das demais microrregiões.

Nas microrregiões do Alto Sertão Alagoano, Sertão do Alto São Francisco e no Agreste esperou-se, a 75 \% de 
Figura 6. Variação da velocidade do vento $\left(u, \mathrm{~m} \mathrm{~s}^{-1}\right)$ média decendial aos percentis a) P25 e b) P75 nas microrregiões do Alto Sertão Alagoano, Sertão do Alto São Francisco, Agreste, Zona da Mata e Litoral Norte.

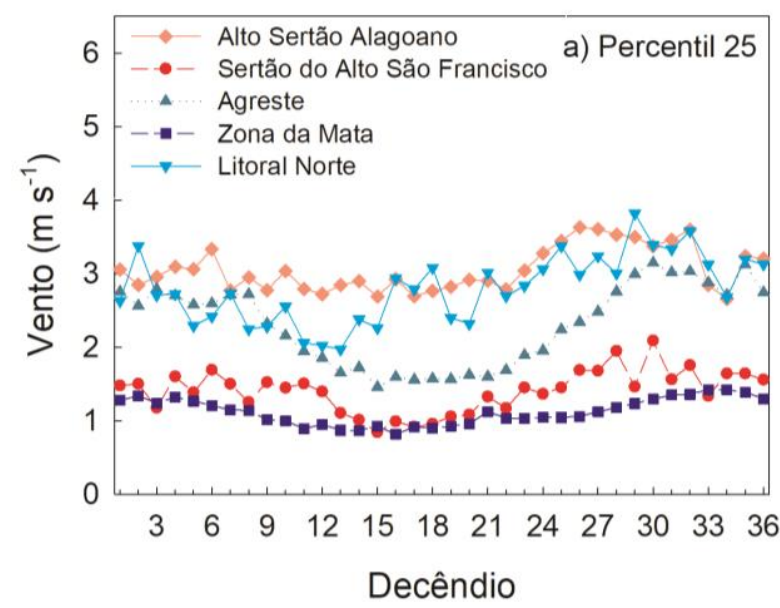

probabilidade, que a velocidade do vento seja considerada adequada (menor que $5 \mathrm{~m} \mathrm{~s}^{-1}$ ) para o crescimento e produção dos frutos do mamoeiro (Clemente \& Marler, 2001). Ao mesmo nível de probabilidade, o Litoral Norte apresentou um decêndio com $u$ superior a $5 \mathrm{~m} \mathrm{~s}^{-1}$. De qualquer forma, no Litoral Norte observaram-se velocidades do vento elevadas $\left(>4 \mathrm{~m} \mathrm{~s}^{-1}\right)$ no período seco da região, que associadas à proximidade do ambiente costeiro, podem causar danos às plantas em função do atrito dos sais marinhos carreados do oceano, descascando folhas e frutos do mamão. Assim, na microrregião do Litoral Norte é indicado para o cultivo do mamão a utilização de quebra-ventos.

\section{Conclusões}

Baseado nas condições bioclimáticas adequadas à produção e ao crescimento potencial do mamão, e nos resultados de probabilidade dos elementos climáticos nas microrregiões estudadas do Estado de Alagoas, conclui-se que:

1 - A precipitação pluvial, sobretudo no período seco e nas microrregiões do Sertão do Alto São Francisco, no Alto Sertão Alagoano e no Agreste, é o principal elemento climático que restringe o crescimento e a produção potencial do mamão em Alagoas. Contudo, essa restrição pode ser contornada com a suplementação de água via irrigação, particularmente no período seco, visando aproveitar a maior disponibilidade de radiação solar desse período;

2 - A Zona da Mata não é climaticamente apta ao cultivo do mamão, em função da insuficiente insolação e da elevada umidade relativa do ar na maior parte do ano; $\mathrm{e}$

3 - As microrregiões do Litoral Norte, Agreste, Alto Sertão Alagoano e Sertão do Alto São Francisco mostram-se aptas ao cultivo do mamão com restrições. Observa-se restrição no período úmido para a insolação no Agreste e umidade relativa do ar elevada no Alto Sertão Alagoano

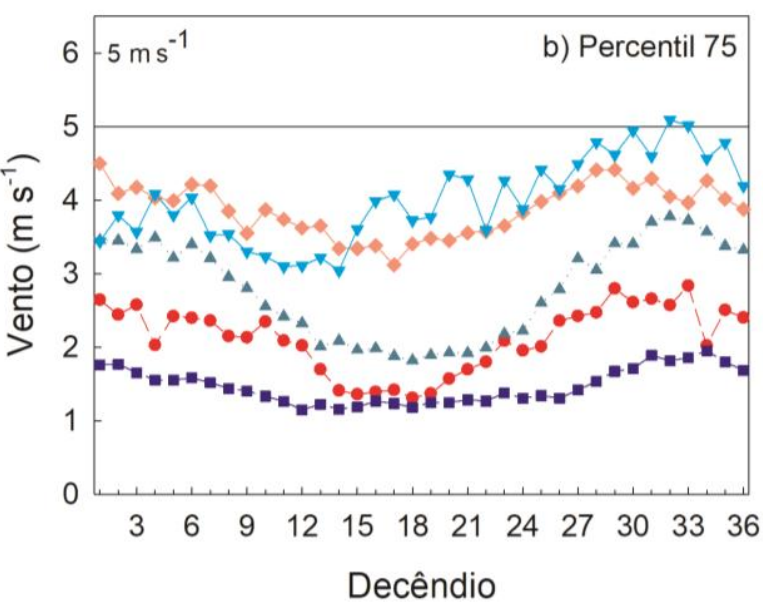

(microrregião de Água Branca), enquanto no período seco do Sertão do Alto São Francisco observa-se baixa umidade relativa do ar, que pode ser atenuada pela irrigação.

\section{Agradecimentos}

À Pró-Reitoria de Pesquisa e Pós-graduação da Universidade Federal de Alagoas - PROPEP/UFAL, à Coordenação de Aperfeiçoamento de Pessoal de Nível Superior - CAPES, ao Conselho Nacional de Desenvolvimento Cientifico e Tecnológico - CNPq e à Fundação de Amparo a Pesquisa no Estado de Alagoas - FAPEAL pela concessão de apoio financeiro e de bolsas de estudo. Ao Instituto Nacional de Meteorologia - INMET por disponibilizarem as séries dos elementos climáticos.

\section{Referências}

AGRIANUAL. Agrianual - Anuário estatístico da agricultura brasileira. São Paulo: FNP consultoria \& comércio/ed. Agros, 2005. 536p.

ALLEN, R.G.; PEREIRA, L.S.; RAES, D.; SMITH, M. Crop evapotranspiration: Guidelines for computing crop water requirements. Rome, FAO, 1998. 300 p. (FAO. Irrigation and Drainage Paper, 56).

CARDIM, A. H. Caracterização da estação de cultivo em Alagoas: análise temporal e espacial. 2003.104 p. Dissertação (Mestrado em Meteorologia) Universidade Federal de Alagoas.

COELHO, E. F.; LIMA D. M.; SOARES, M. A. A.; CALDAS, R. C. Produção do mamoeiro cultivar Tainung $n^{\circ} 1$ sob diferentes regimes de irrigação nos Tabuleiros Costeiros do Recôncavo Baiano. In: CONGRESSO BRASILEIRO DE FRUTICULTURA, 2002, Belém. Anais. (CD-Rom).

CRANE, J. H. Papaya growing in the Florida home landscape. Florida, USA: IFAS, 2005. (Horticultural Sciences Department, HS11). 8 p.

CUNHA, G. R.; ASSAD, E. D. Uma visão geral do número especial da RBA sobre zoneamento agrícola no Brasil. Revista Brasileira de Agrometeorologia, v. 9, n. 3, p. 377-385, 2001.

FIGUEIREDO, J. O. G. R. Distribuição espacial da pluviometria em Alagoas com ênfase à variabilidade causada pelos padrões de temperatura da superfície do mar. 2002. 140 p. Dissertação (Mestrado em Meteorologia) Universidade Federal de Alagoas. 
GOIS, G.; SOUZA, J. L.; SILVA, P. R. T.; OLIVEIRA JÚNIOR, J. F. Caracterização da desertificação no estado de Alagoas utilizando variáveis climáticas. Revista Brasileira de Meteorologia, v. 20, p. 301-314, 2005.

CLEMENTE, H.S.; MARLER, T. E. Trade winds reduce growth and influence gas exchange patterns in papaya seedlings. Annals of Botany, v. 88, p. 379-35, 2001.

MARIN, S. L. D.; GOMES, J. A.; SALGADO, J. S. Recomendações para a cultura do mamoeiro dos grupos ‘Solo' e ‘Formosa' no Estado do Espírito Santo. 4 ed. Vitória: EMCAPA, 1995. 57p. (Circular Técnica, 3).

MARLER, T. E.; GEORGE, A. P.; NISSEN, R. J.; ANDERSEN, P. C. Miscellaneous tropical fruits. In: Handbook of environmental physiology of fruits crops - Subtropical an tropical crops. Boca Raton: 1994. v. 2. p. 199-224.

MEDINA, J. C. Cultura. In: INSTITUTO DE TECNOLOGIA DE ALIMENTOS. Mamão. 2.ed. Campinas: ITAL, 1989. p. 1-178. (Série Frutas Tropicais, 7)

MOLION, L. C. B.; BERNARDO, S. Uma revisão da dinâmica das chuvas no Nordeste brasileiro. Revista Brasileira de Meteorologia, v. 17, p. 1-10, 2002.

MORAES, B. C.; COSTA, J. M. N.; COSTA, A. C. L. Variação espacial temporal da precipitação no Estado do Pará. Acta Amazônica, v.35, p. 207-214, 2005.

NERY, J. T.; MARTINS, M. L. O. F.; BALBO, M. C. Correlação da precipitação do estado do Paraná com a anomalia da temperatura da superfície do mar no Pacífico equatorial. Revista Brasileira de Agrometeorologia, v. 10, p. 305-316, 2002

NISHINA, M.; ZEE, F.; EBESU, R.; ARAKAKI, A.; HAMASAKI, R.; FUKUDA, S.; NAGATA, N.; CHIA, C. L.; NISHIJIMA, W.; MAU, R.; UCHIDA, R. Papaya production in Hawaii. Hawaii, USA: CTAHR, 2000. (Fruits and Nuts, 3). 8 p.

OMM. Agrométéorologie opérationnelle: recueil de notices phénologiques. Genebra, Suíça: Organização Météorologique Mondiale, 1991. 258 p.
OLIVEIRA, A. M. G.; FARIAS, A. R. N.; SANTOS FILHO, H. P. S.; OLIVEIRA, J. R. P.; DANTAS, J. L. L.; SANTOS, L. B.; OLIVEIRA, M. A.; SOUZA JÚNIOR, M. T.; SILVA, M. J.; ALMEIDA, O. A.; NICKEL, O.; MEDINA, V. M.; CORDEIRO, Z. J. M. Mamão para exportação: aspectos técnicos de produção. Brasília: EMBRAPA, SPI, 1994. 52p. (Série Publicações Técnicas FRUPEX, 9).

PEREIRA, A. R.; VILLA NOVA, N. A.; SEDIYAMA, G. C. Evapo(transpi)ração. Piracicaba, SP: FEALQ, 1997, 183 p.

KASSAM, A.H. Multiple cropping and rainfed crop productivity in Africa. In: Report on the Second FAO/UNFPA Expert Consultation on Land Resources for Populations of the Future. Rome, FAO: 1980 p. 123-195.

SEAGRI, disponível em <Seagri.ba.gov.br/mamão.htm>. Acesso em: 21 jan. 2007.

SIMANE, B.; STRUIK, P. C. Agroclimatic analysis: a tool for planning sustainable durum wheat (Triticum turgidum var. durum) production in Ethiopia. Agriculture, Ecosystems and Environment, v. 47, p. 31-46, 1993.

SIQUEIRA, D. L.; BOTREL, N. Clima e solo para a cultura do mamoeiro. Informe Agropecuário, v.134, p.8-9, 1986.

SOUZA, J. L.; MOURA FILHO, G.; LYRA, R.F.F.; TEODORO, I., SANTOS, E.A.; SILVA, J.L. SILVA, P.R.T.; CARDIM, A.H.; AMORIM, C.A. Análise da precipitação pluvial e temperatura do ar na região do Tabuleiro Costeiro de Maceió, AL, período 1972-2001. Revista Brasileira de Agrometeorologia, v. 11, p. 131$141,2004$.

SPIEGEL, M. R. Probabilidade e estatística. São Paulo, SP: McGraw-Hill, $1978,518 \mathrm{p}$.

XAVIER, T. M. B. S.; XAVIER, A. F. S. Classificação e monitoração de períodos secos ou chuvosos e cálculo de indices pluviométricos para a região Nordeste do Brasil . Revista Brasileira de Engenharia Caderno de Recursos Hídrcos, v. 5, p. 7-31, 1987. 


\title{
$\overline{\text { agrometeoros }}$ \\ REVISTA DA SOCIEDADE BRASILEIRA DE AGROMETEOROLOGIA
}

\section{Bioclimatic characterization of microregions in the State of Alagoas, Northeast Brazil, for papaya cropping}

\author{
Gustavo Bastos Lyra ${ }^{1}$, José Leonaldo de Souza ${ }^{2(*)}$ Erikson Amorim dos Santos ${ }^{2}$ and Guilherme Bastos Lyra ${ }^{2}$ \\ ${ }^{1}$ Universidade Federal Rural do Rio de Janeiro. Rodovia BR 465, km 07, s/n, Zona Rural, CEP 23890-000 Seropédica, RJ, Brazil. E-mail: gblyra@gmail.com \\ ${ }^{2}$ Universidade Federal de Alagoas. Av. Lourival Melo Mota, s/n,Tabuleiro dos Martins, CEP 57072-900 Maceió, AL, Brazil. \\ E-mails: jls@ccen.ufal.br, saerikson@hotmail.com and gbastoslyra@gmail.com \\ ${ }^{(*)}$ Corresponding author.
}

\section{ARTICLE INFO}

\section{Article history:}

Received 15 April 2020

Accepted $1^{\text {st }}$ July 2020

\section{Index terms:}

percentile

statistical climatology

humid and dry seasons

Carica papaya

\section{ABSTRACT}

The aims of this study were to evaluate the bioclimate characteristics of five microregions in Alagoas state, Brazil, to cropping of papaya. The microregions were: Northern Coastal, Humid Zone, Hinterland, Interior of High São Francisco and High Interior of Alagoas. The ten-day periods (decade) of air temperature and relative humidity, wind speed, sunshine hours, total rainfall and reference evapotranspiration from long-term series (more than 30 years) were used for this characterization. For Humid Zone the series of data were from 1973 to 2003, while for the other microregions the series were from 1977 to 2006. The probability of these climatic elements at 25,50 and 75 percentiles were determined. The decade precipitation was only about half of the papaya water requirements (>33 $\mathrm{mm}$ ) in the Northern Coastal (53 \%) and Humid Zone (44\%). Relative humidity in the rainy period was below the appropriate threshold ( $<60 \%)$ in $44 \%$ of the decades in the Interior of São Francisco, during the less rainy period. The relative humidity, during the wet period, in the Humid Zone was well above the desirable threshold ( $>85$ $\%)$, while the mean observed sunshine hours ( $<5.5 \mathrm{~h}$ ) was lower than the required for papaya. The climatic characteristics of Humid Zone are not appropriate for the papaya crop. The other microregions showed restrictions, mainly related to precipitation, which could be supplemented by irrigation. 